\title{
Sabit Yataklı Kurutucu ile Fındık Kavurma Prosesinde Kurutma Kinetiği Analizi
}

\author{
Mükrimin Şevket GÜNEY ${ }^{*}$ \\ ${ }^{1}$ Giresun Üniversitesi, Makine Mühendisliği, Giresun, Türkiye
}

Geliş Tarihi: 10.03 .2020

*Sorumlu Yazar: guney80@giresun.edu.tr Kabul Tarihi: 29.05.2020

\section{Öz}

Fındık özellikle çikolata endüstrisinde yaygın kullanılan önemli bir üründür. Dünya ticaretinde yıllık 3 milyar dolarlık bir yekün oluşturmaktadır. Yaklaşık 2 milyar dolarlık miktar ile ülkemizin önemli bir tarımsal ürün ihracat kalemini teşkil etmektedir. Fındık ürününde kavurma işlemi yoğun biçimde uygulanmaktadır. Çok yönlü parametrelere bağlı olan kavurma işlemi ürün üzerinde de belirgin birçok değişimlere yol açmaktadır. Kavurma firını tarzları, hava hızı ve hareketleri gibi faktörler önem kazanmaktadır. Bu çalışmada domestik kavurma firınında 140 oC sıcaklıkta findık içlerinin kavrulması, nem miktarının zamanla değişimi incelenmesi ve ince tabaka kurutma kinetiği modellemesi yapılmıştır.

Anahtar Kelimeler: Fındık, Kavurma, Sabit yatak, Kurutma kinetiği.

\section{Drying Kinetics Analysis in Hazelnut Roasting Process with Fixed Bed Dryer}

\begin{abstract}
Hazelnut is an important product that is widely used especially in chocolate industry. It constitutes a total of \$ 3 billion annually in world trade. It generates an annual export volume of approximately 2 billion dollars. Therefore, it constitutes an important agricultural product export item of our country. The roasting process is applied intensely in hazelnut product. The roasting process, which depends on the versatile parameters, causes significant changes on the product. Factors such as roasting oven styles, air speed and movements gain importance. In this study, the roasting of hazelnut kernels at a temperature of $140 \mathrm{oC}$ was carried out in the domestic roasting oven. The change in the amount of moisture over time was examined. Thin layer drying kinetics were modeled.
\end{abstract}

Keywords: Hazelnut, Roasting, Fixed bed, Drying kinetic. 


\section{Giriş}

Fındık yılda yaklaşık 2 milyar dolarlık ihracat geliri ile ülkemiz için önem arz etmektedir. Dünya toplam fındık üretiminin yaklaşık \%65’i ülkemizde gerçekleştirilmektedir (Güney ve Güner, 2018). Türkiye'de yaklaşık 440.000 üretici, 700.000 hektar alanda fındık üretimi yapmaktadır. Fındık, \% 80 oranında çikolata sanayinde dilinmiş, kıyılmış, öğütülmüş biçimde; \%10-12 oranında pastacılık-bisküvi-unlu mamuller sektörlerinde; \%3-4 oranında da çerez olarak, kalanı dondurma sektöründe ve yağ sanayinde kullanılmaktadır (URL-1, 2019)

Çikolata sanayinde ve kuru yemiş olarak tüketilen findıkların özellikle kavrulmuş olmaları istenmektedir. Kavurma, yağlı tohumlar ve kuruyemişlere lezzet, renk ve yapısal doku gibi özelliklerin kazandırılmasına yönelik uygulanan bir 1sıl işlemdir. İşlem doğası gereği ürün neminin azalmasına da yol açmaktadır. Kavurma esnasında ürün nemi \%6 dan \% 1-3 arasında değerlere düşürülmektedir. Ancak işlemin ana hedefi kurutma değildir. (Alamprese ve ark. 2009). Fındık kavurmada kullanılan en yaygın yöntem, sürekli çalışan yürüyen bantlı konvektif tip kurutma/kavurma sistemleridir. (Perren ve Escher, 2007). Endüstriyel kavurma yüksek sıcaklıkta kısa ve belirli sürelerle uygulanan bir işlemdir. Nihai üründeki değişimlere işlem sıcaklığı, hava hızı, ürünün şekli ve büyüklüğü, bant üzerindeki ürün yüksekliği, işlem süresi, son soğutmanın niteliği gibi faktörler etki etmektedir [Heldman ve Dennis, 2006], [Brennan, 2008]

Fındık kavurma enerji yoğun bir prosestir. İşlem esnasında belirgin biçimde ürün nemine, sterilizasyona ve ürün toplam lezzetine etki edilmektedir (Güney ve Tepe, 2016). Dolayısıyla işlem parametrelerinin kontrolü elzem olmaktadır. Kavurma eş zamanlı 1sı ve kütle transferine dayanmaktadır. Sıcak hava üflemeli konveyör bantlı sistemler düşünüldügüüde ürün dış yüzeyinden sıcak hava yoluyla ürüne 1sıl enerji verilmekte ve ürün üzerinde yüzeyden içeriye doğru bir sıcaklık artışı oluşturulmaktadır. Ürün içindeki nem ise ürün iç noktasından ve diğer bölgelerden ürün yüzeyine doğru yönlenmekte ve ürün yüzeyinden 1sıl enerjiyi sağlayan sıcak hava vasıtasılyla uzaklaştırılmaktadır. Proses boyunca ürün dış yüzeyinde en yüksek sıcaklık hasıl olmakta ve ürün içinde radyal yönde azalarak sıcaklık gradyanı gelişmektedir. Sterilizasyon bakımından kritik bölge ürün iç boşluğunun da oluştuğu merkez noktasıdır. Fındık şekil ve biçimi bakımından küresel cisim kabul edilebilmektedir. Araştırmanın tarzına ve çözüm yöntemine uygun olarak içi boş veya içi dolu küresel cisim yaklaşımı yapılabilmektedir. Nem içeriği analizi, malzeme kalitesinin kritik bir bileşenidir (URL-2, 2020). Ayrıca raf ömrüne de doğrudan etki etmektedir. Bu çalışmada sabit yataklı sıcak hava üflemeli domestik firınlarda kavurma işlemi esnasında iç fındıkların nem analizleri ve kurutma kinetikleri deneysel olarak incelenecektir, bunun yanı sıra ince tabaka kabulü ve ampirik denklem ile gelişim eğrileri yaklaşımları belirlenecektir. 


\section{Materyal ve Metot}

Kurutma esnasında buharlaşan nemin ürün yüzeyine hareketinin difüzyon yoluyla olduğu görüşü hakimdir ve iç fındıklar küresel cisim kabul edilebilmektedir [Mjumdar, 2006).

\subsection{Materyal}

Bu çalışmada kullanılan findıklar Tombul cins olup Ordu ili Öceli köyünden temin edilmiştir. Bu bölgede denizden yükseklik 110-160 metre arasındadır. Hasat sonrası güneş altında doğal olarak kurutulan findıklar uygun bekletme şartlarında iyi havalandırılmış ahşap türevi sepetlerde 3 ay kadar bekletilmişlerdir. Kullanılan iç fındıkların çap büyüklükleri 12-13 mm olarak tespit edilmiştir. Kavurma işlemi domestik tip firında turbo fonksiyonu ile 140 oC sıcaklıkta uygulanmıştır.

\subsection{Deney Düzeneği}

Sabit yataklı kavurma fırını olarak ankastre tarz 2 kW gücünde Silverline marka fırın kullanılmıştır. $\mathrm{Bu}$ fırınlarda alt ve üst 1sıtıcı resistans bulunmaktadır. Turbo fonksiyonlu olarak kullanıldığında alt ve üst resistanslar çalışır durumda ve fan ile üflenmek suretiyle turbo fonksiyonu yerine getirilmektedir. Sıcaklık ayarı gazlı termostat düzeneği ile sağlanmaktadır. Bu tarz firınlarda üst resistansların ürüne bakan yönü açık olduğundan ışınım etkisi de kavurma işlemine pozitif olarak katkıda bulunmaktadır.

Kavurulacak ürünün tepsi içinde fırındaki yerleşimi Şekil 1 de verilmektedir. Fırın üst resistansı önü açık olduğundan bu kısma boş bir tepsi yerleştirilerek doğrudan ışınım etkisi önemli ölçüde azaltılmaktadır.

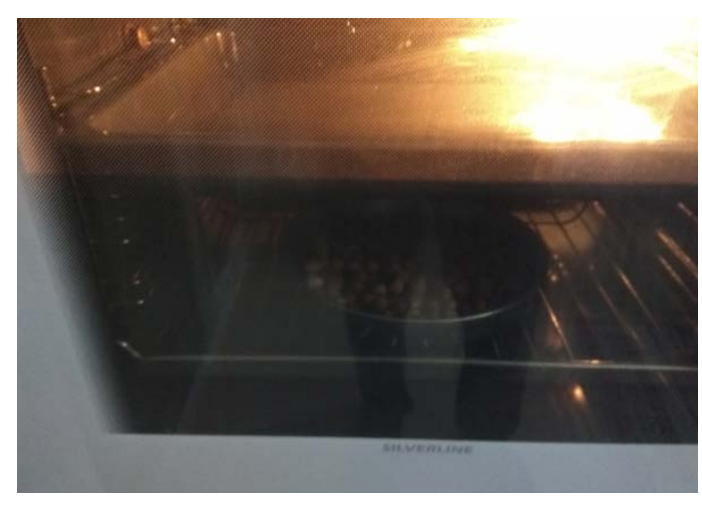

Şekil 1. Kavrulacak ürünün firın içi yerleşimi 
Şekil 2 de ise nem ölçer cihazı verilmektedir. Nem ölçümüm RADWAG marka MA 60.3Y model cihaz kullanılarak gerçekleştirilmiştir. Bu cihaz infrared ısıtmalı ve termogravimetrik yöntem ile nem miktarını belirlemektedir.

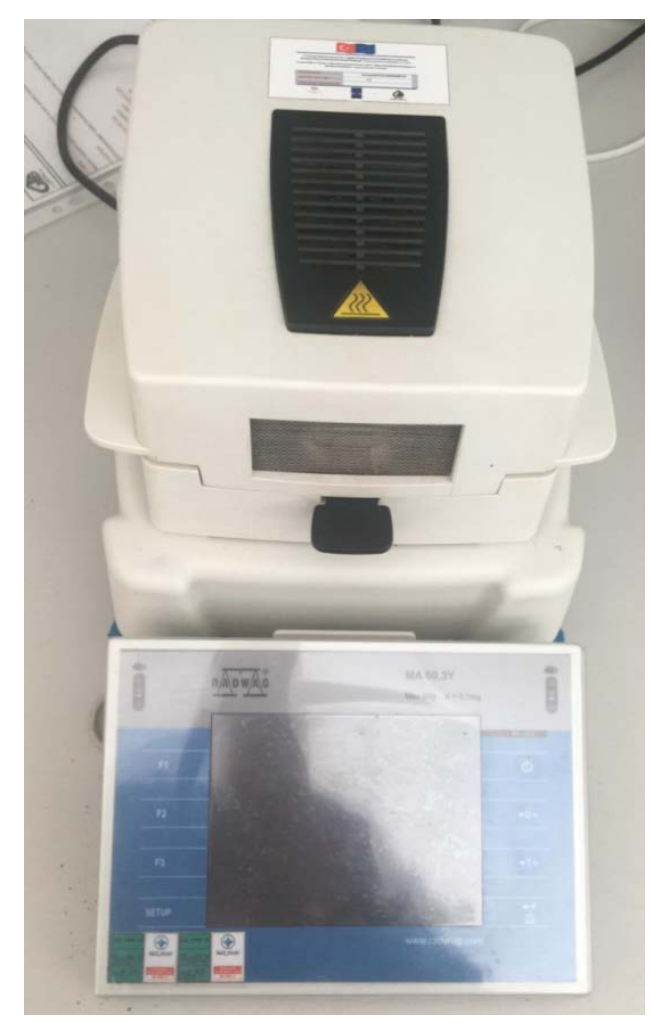

Şekil 2. Nem ölçer RADWAG MA 60.3Y

\subsection{Deney Prosedürü}

Kavurma işleminin icrasında domestik tip sabit yataklı sıcak hava sirkülasyonlu fırın kullanılmıştır. Kavurma işlemi $140{ }^{\circ} \mathrm{C}$ sıcaklıkta 24 dakika boyunca uygulanmıştır. Fırın boş iken işlem sıcaklığına getirilmiştir. Ürünler tek tepsi kullanılıp ve tepsi içinde tek sıra olarak firının alt tabandan $10 \mathrm{~cm}$ yüksekliğe yerleştirilmiştir. Ölçüm numuneleri altışar adet ve iki dakikalık aralıklarla alınmışlardır. Alınan numuneler soğumalarını takiben tekrar nem almalarını engellemek amaçlı kilitli poşet ambalajlara yerleştirilmektedir. Nem ölçümleri termo gravimetrik usul ile belirlenmiştir.

\subsection{Modelleme}

Kurutma kinetiği ürün nem miktarının zamanla bağlı değişimi olarak verilmektedir [Wang ve ark., 2011). Proses boyunca herhangi bir andaki kuru ürün bazlı nem miktarı Mt (kg nem/kg kuruürün) ile gösterilmektedir. 


$$
M_{t}=\frac{m_{n e m}}{m_{k b}}=\frac{m_{t}-m_{k b}}{m_{k b}}
$$

Burada

mkb: kuru bazlı ürün kütlesi (kg),

$\mathrm{m}_{\text {nem: }}$ ürün içindeki nem kütlesi $(\mathrm{kg})$

$\mathrm{m}_{\mathrm{t}} \quad$ herhangi $\mathrm{t}$ anındaki ürünün kütlesidir $(\mathrm{kg})$.

MR ile boyutsuz nem oranı tanımlanmaktadır. Boyutsuz nem oranı bağıntısı aşağıda verilmektedir.

$$
M R=\frac{M_{t}-M_{e}}{M_{i}-M_{e}}
$$

Burada

$\mathrm{M}_{\mathrm{e}}$ : ürünün denge nem miktarı

$\mathrm{M}_{\mathrm{i}}$ : ürünün başlangıç nemidir.

Ürün denge nem miktarı aşağıda verilen bağıntı ile belirlenebilmektedir (Andre ve ark., 2017)

$$
M_{e}=\left[\frac{\ln (1-B N)}{-0.003(T+85.5418)}\right]^{\left(\frac{1}{1.7518}\right)}
$$

\section{Burada}

BN: ondalıklı bağıl nem

T: $\quad$ sicakliktır $\left({ }^{\circ} \mathrm{C}\right)$.

Diğer bir yaklaşım ise denge nem değerinin başlangıç ve anlık ürün nem değerlerinden çok daha düşük olduğu varsayımı ile yapılabilmektedir. Bu durumda

$$
M R=\frac{M_{t}}{M_{i}}
$$


olacaktır.

Kurutma hızı $\mathrm{KH}$ ile gösterilebilir ve $\mathrm{t}$ zamanındaki nem miktarı ile $\mathrm{t}+\mathrm{dt}$ zamandaki nem miktarı araındaki farkın dt zaman aralığına oranı biçimindedir.

$$
K H=\frac{d M R}{d t}
$$

Findık kavurma prosesi belirlenmesinde kullanılan matematik modeller Henderson ve Pabis, Logaritmik ve İki terimli modellerdir. Söz konusu model denklemleri aşağıda verilmektedir.

Henderson ve Pabis $\quad M R=A e^{-k t}$

(Kavak Akpınar ve Demirci, 2018)

Logaritmik

$$
M R=B+A e^{-k t}
$$

[Tumba, 2018)

İki terimli

$$
M R=A e^{-k t}+C e^{-n t}
$$

[André ve ark., 2017)

Literatürde sık kullanım bulan eşitlikler kavurma prosesi esnasında iç findıkların kurutma kinetiklerini tanımlamada değerlendirilmiştir. Deneysel verilerden alınarak oluşturulan boyutsuz nem oranı vasıtasıyla lineer olmayan regresyon analizi yöntemi kullanılarak, ince tabaka kurutma kinetiğ ampirik denklemi elde edilmektedir. Model parametreleri Tablo 1 de verilmektedir.

Tablo 1. Kurutma eğrileri modelleme parametreleri

\begin{tabular}{lccccccc}
\hline Modeller & $\mathrm{A}$ & $\mathrm{B}$ & $\mathrm{C}$ & $\mathrm{k}$ & $\mathrm{n}$ & $\mathrm{r}$ & $\mathrm{R}^{2}$ \\
\hline $\begin{array}{l}\text { Henderson } \\
\text { ve Pabis }\end{array}$ & 1,0842 & & & 0,0614 & & 0,9851 & 0,9705 \\
\hline Logaritmik & 1,1456 & $-0,0692$ & & 0,0549 & & 0,9854 & 0,971 \\
\hline İki terimli & $-0,1771$ & & 1,1762 & 1,0347 & 0,0682 & 0,9928 & 0,9857 \\
\hline
\end{tabular}

\section{Bulgular ve Tartışma}


Fırın içindeki sıcaklık değişimi Şekil 3'te verilmektedir. Domestik tarz firınlar genellikle gazlı termostat tertibatı ile donatılmış olduğundan sıcaklık değişimi yaklaşık $15{ }^{\circ} \mathrm{C}$ 'lik bir aralıkta olmaktadır. Ön ısıtma yapılmak suretiyle $140{ }^{\circ} \mathrm{C}$ 'ye getirilen fırına bu esnada kapak açılmak suretiyle ürünler tepsi içinde yerleştirilmiştir. Bu esnada firın içinde bir miktar sıcaklık düşüşü gözlenmektedir.

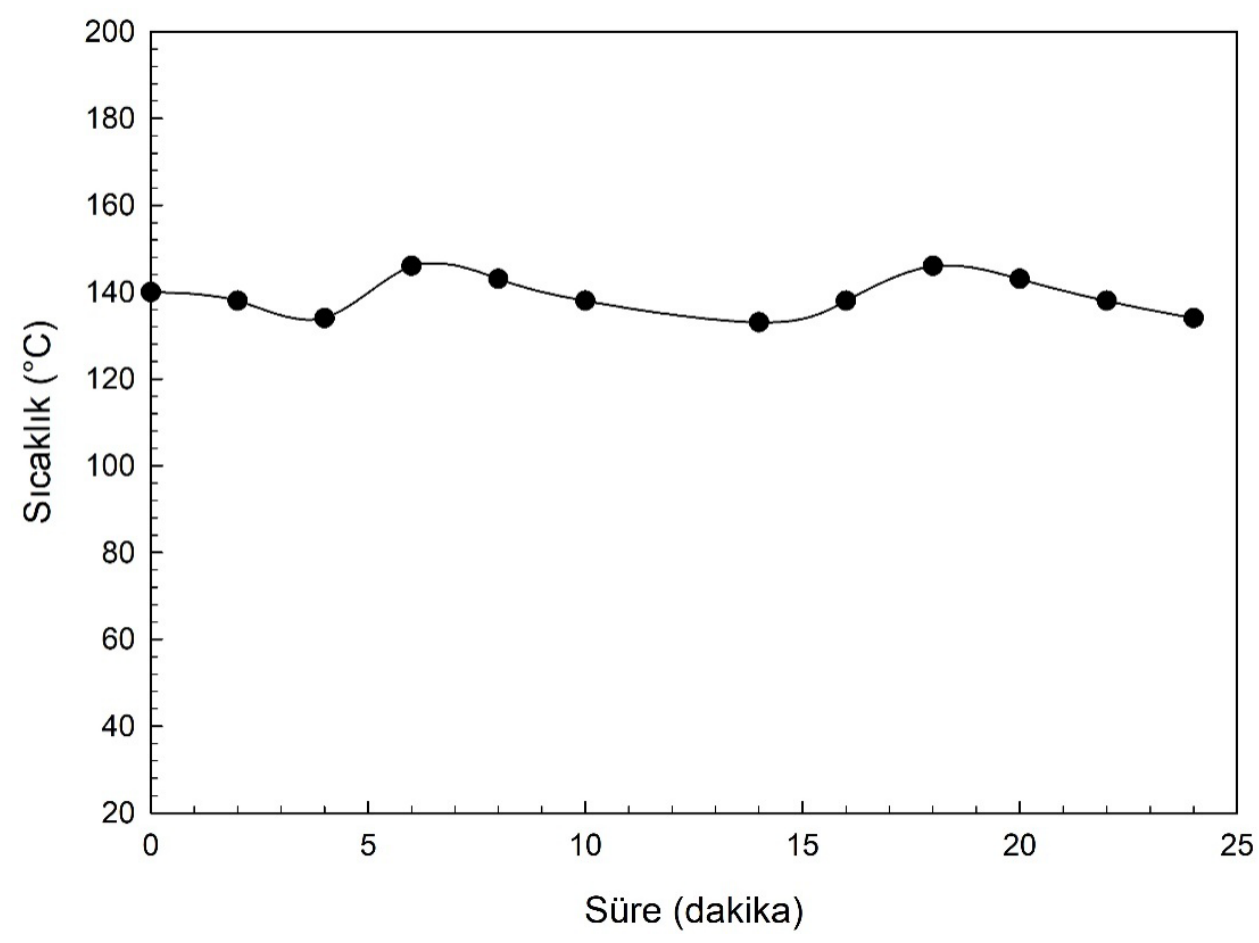

Şekil 3. Kavurma esnasında fırın içi sıcaklık değişimi

Üç farklı denklem yaklaşımıyla elde edilen kuru bazlı ürün nem miktarının zamanla değişimi sırasıyla Şekil 4, 5 ve 6 da sunulmaktadır. 


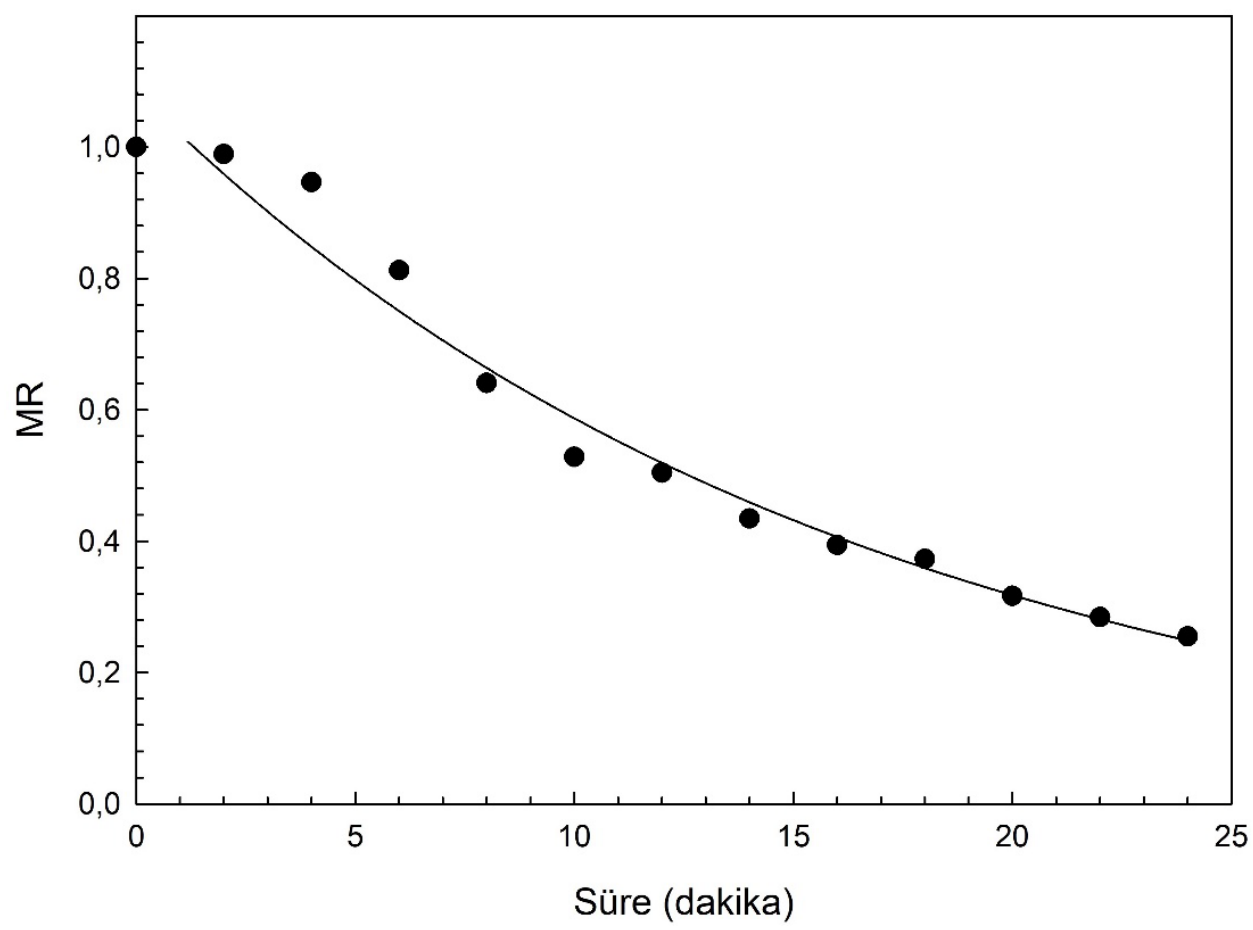

Şekil 4. Henderson ve Pabis model denklemiyle elde edilen kurutma eğrisi

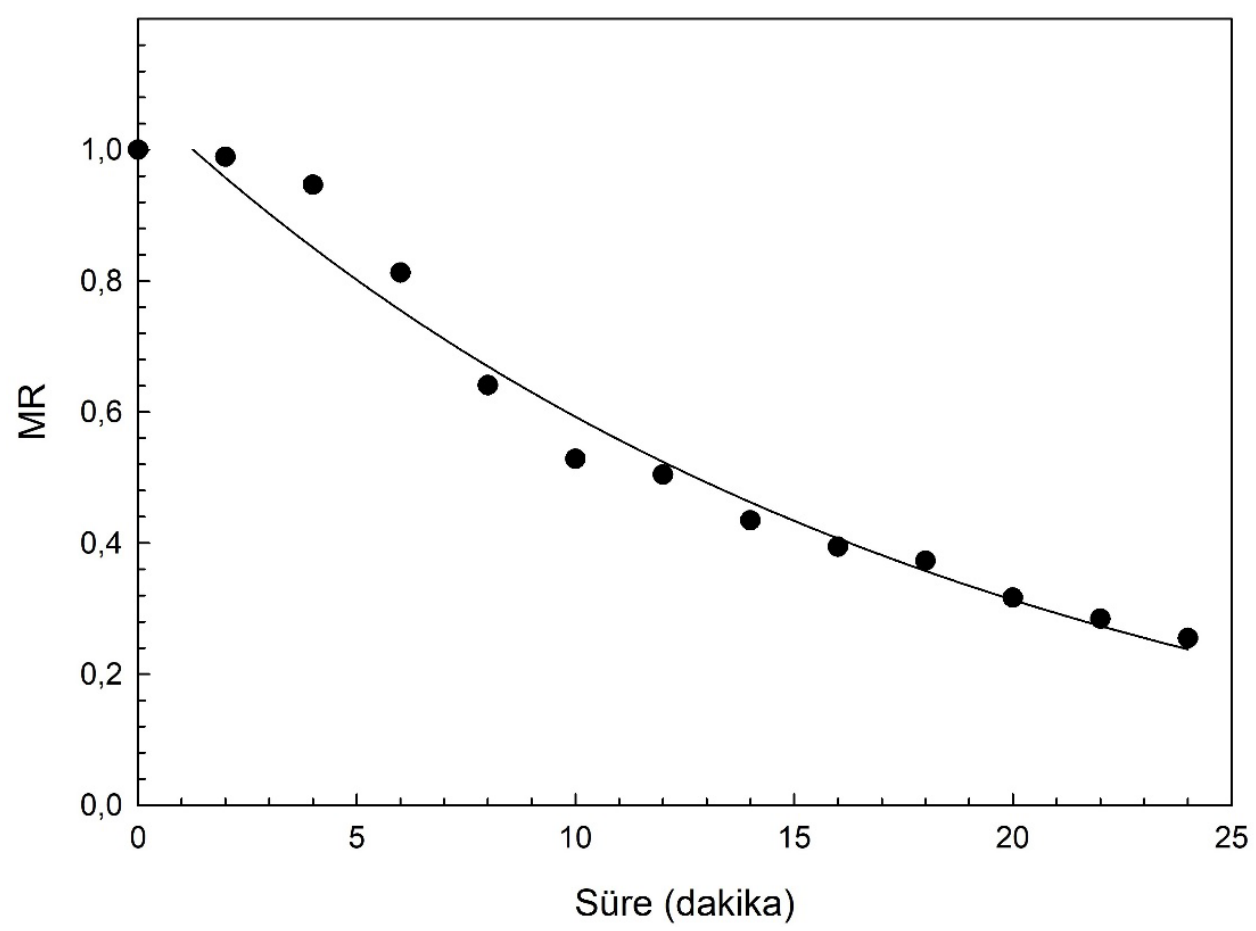

Şekil 5. Logaritmik model denklemiyle elde edilen kurutma eğrisi 


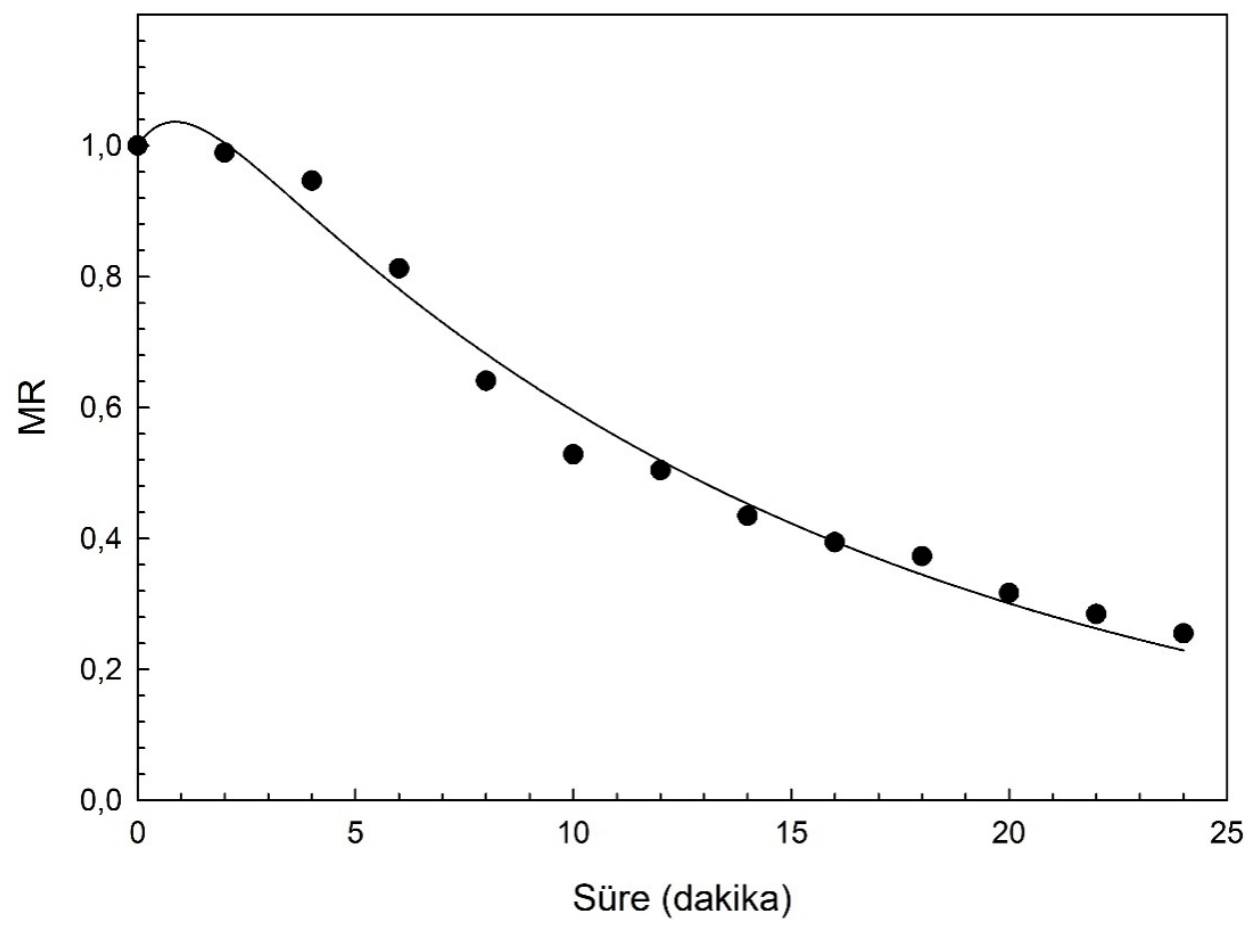

Şekil 6. İki terimli model denklemiyle elde edilen kurutma eğrisi

Henderson ve Pabis model yaklaşımı kullanılarak elde edilen kurutma hızının zamana bağlı değişimi ise Şekil 7'de verilmektedir.

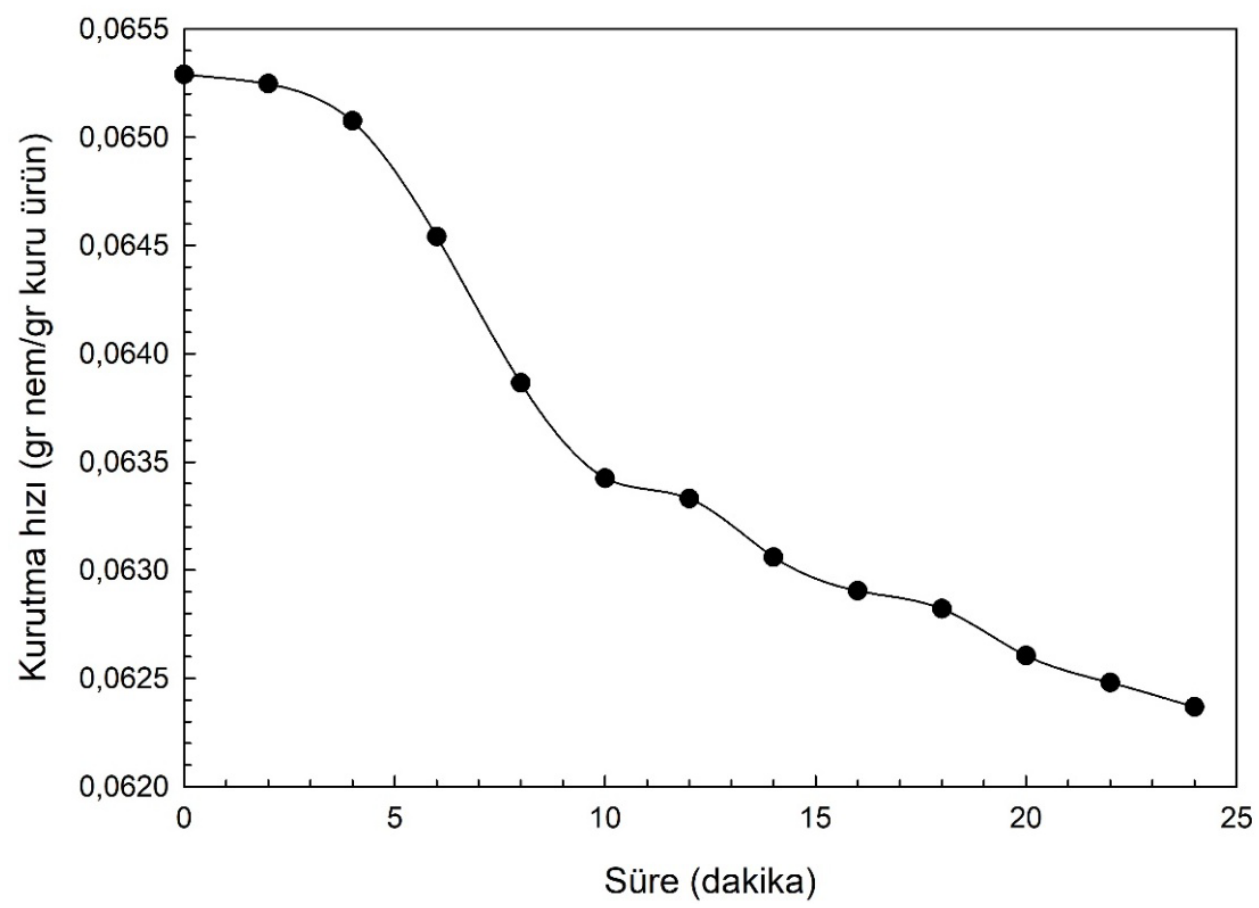

Şekil 7. Proses süresince kurutma hızı değişimi 
Kavurma nem miktarları \%6 ve daha az olan iyi kurutulmuş kabuklu fındıklardan elde edilen fındık içlerine uygulanan bir süreçtir. Kurutma prosesleri genel gelişimlerine bakıldığında ısıtma, sabit kurutma hızlı, ve azalan kurutma hızlı periyotlar olarak üç kısma ayrılmaktadır. Daha ayrıntılı inceleme istenirse azalan kurutma hızlı periyot da kendi içinde birinci ve ikinci azalan kurutma hızlı periyotlar olarak değerlendirilebilmektedir. Isıtma periyotunda nem azalması çok cüzi olacaktır, bu nedenle ilgili fazın kinetik modelleme denklemleri yardımıyla yaklaştırılması hedeflenen bilgilerin eldesinde çok anlamlı olmayacaktır. Kurutma hızı eğrisi incelendiğinde 1sıtma periyotunun yaklaşık ilk dört dakikadan itibaren sonlandığı görülmektedir. Bu andan itibaren onuncu dakikaya kadar birinci azalan kurutma hızlı periyot ve takiben ikinci azalan kurutma hızlı peryodun geliştiği anlaşılmaktadır. Yalnızca model parametrelerine incelendiğinde iki terimli modelin daha yüksek değerler verdiği gözlenmektedir. Bu durum ısıtma periyodu esnasındaki değerler hesaplara katıldığından ortaya çıkmaktadır. Gerçek kurutmanın yani nem azalmasının başladığı andan itibaren ise Henderson-Pabis ile Logaritmik denklem modellerinin eğrilerinin deneysel değerlere çok yakın geliştiği gözlenmektedir. Özellikle son on dakika değerleri ele alındığında Henderson ve Pabis model yaklaşımının daha yakın değerler gösterdiği belirlenmektedir.

\section{Sonuçlar ve Öneriler}

Domestik tarz firınlarda kavurma işlemi sık uygulanmaktadır. Fırın içinde birden fazla tepsi bulunduğundan özellikle üst resistansları alt kısımlarının açık olmaları dolayısıyla üst tepside 1şınım etkileri ile daha hızlı bir kavurma/kurutma etkisi olmaktadır. Homojenliği sağlamak amacıyla bu resistansın altına boş bir tepsi konulması uygun bir yaklaşım olarak görülmektedir. Düşük nem içerikli kuru ürünlerin kavrulması işleminde sabit kurutma hızlı peryot gözlenmemektedir. Oluşan kurutma periyotlarının ısıtma, birinci azalan kurutma hızlı ve ikinci azalan kurutma hızlı periyotlar olarak ayrılmasının uygun olduğu anlaşılmaktadır. Her üç periyot birbirinden farklılaşmış karekteristikler göstermektedir. Her üç periyotu da içine alacak biçimde prosesin tamamının tek bir model denklem ile yaklaştırılması çok başarılı olamayabilecektir. Isıtma periyotu için iki terimli, birinci azalan kurutma hızlı peryod için Logaritmik ve ikinci azalan kurutma hızlı periyot için Henderson ve Pabis modelleri daha yüksek yaklaşımlar göstermektedir. Farklı kurutma periyotlarının sürelerinin belirlenmesi sonucunda, her bir periyot için farklı modellerin alınması ve tüm prosesin bu modellerin kombinasyonu ile değerlendirmesi daha uygun olacaktır.

\section{Teşekkür}


Çalışma esnasındaki değerli destek ve yardımlarından dolayı Dr. Öğr. Üyesi Hasan Onur TAN’a, Mühendis Güray ZOMP’a ve Giresun Ticaret Borsası yetkililerine samimi duygularımla teşekkür ederim.

\section{Kaynaklar}

Alamprese C., Ratti S., Rossi M., (2009) Effects of roasting conditions on hazelnut characteristics in a twostep process, Journal of Food Engineering, Volume 95, Issue 2, Pages 272-279.

André L. D. Goneli A.L.D., Araujo W. D.,Filho C. P. H., Martıns E.A. S., Oba G. C.,.(2017). Drying kinetics of peanut kernels in thin layers , Eng. Agríc., Jaboticabal, v.37, n.5, p.994-1003.

Brennan J. G., (2008) Food Processing Handbook,,Wiley-VCH Verlag GmbH \& Co. KGaA

Guney M.S.,, Tepe Y.,, (2016). Improving the roasting process and efficiency of hazelnut, Advances in Food Science Volume 38, No 3, pp 109, 116.

Güney M. S., , Güner F., (2018). Fındık Tarımında Durum Analizi, Makineli Hasat Gerekliliği ve Hasat Makinelerinin Sınıflandırılması, Türk Tarım - Gıda Bilim ve Teknoloji Dergisi, 6(9): 1141-1147.

Heldman D., Dennis R; (2006). Handbook of Food Engineering, Second Edition, vol. 6..

Kavak Akpınar E., Demirci S., (2018). Mathematical models to determine of thin layer drying kinetic of ginger slices., Vol 8, Number 2, European Journal of Technic (EJT)

Mujumdar A. S., (2006). Book Review: Handbook of Industrial Drying, Third Edition, vol. 25, no. 6. CRC Press

Perren, R., Escher, F., (2007). Nut roasting technology and product quality. The Manufacturing Confectioner 87 (6), 65-75

Tumba K., (2018). Convectıve air drying characteristics of ground macadamia nuts., Scientific Study \& Research Chemistry \& Chemical Engineering, Biotechnology, Food Industry., 19 (3), pp. 243 - 255

Wang Q.,* Z Zhang L., Bai J., Liu H., Li S., (2011). The Influence of microwave drying on physicochemical properties of Liushuhe oİL shale., Oil Shale, Vol. 28, No. 1, pp. 29-41., Estonian Academy Publishers].

URL-1, (2019) (Findik Raporu 2018, http://www.zmo.org.tr/genel/bizden_detay.php?kod=30070\&tipi=17\&sube=0 (27.11.2019).

URL-2, (2020) https://www.scientistlive.com/content/what-moisture-content-analysis (27.02.2020) 